R. Humphreys

\title{
Game Birds: the ethics of shooting birds for sport
}

\section{Abstract}

This paper aims to provide an ethical assessment of the shooting of animals for sport. In particular, it discusses the use of partridges and pheasants for shooting. While opposition to hunting and shooting large wild mammals is strong, game birds have often taken a back seat in everyday animal welfare concerns. However, the practice of raising game birds for sport poses significant ethical issues. Most birds shot are raised in factory farming conditions, and there is a considerable amount of evidence to show that these birds endure extensive suffering on these farms. Considering the fact that birds do have interests, including interests in life and not suffering, what are the ethical implications of using them for blood sports? Indeed, in light of the suffering that game birds endure in factory farms, it may be that shooting such birds for sport is more morally problematic than other types of hunting and shooting which many people are often fiercely opposed to, for while it seems plausible to say that some animals may be harmed more by death than others (due to, say, their greater capacities), there may be harms that are worse than death (such as a life of intolerable suffering). The objective of this paper is to assess the ethics of shooting animals for sport, and in particular the practice of raising game birds for use in blood sports, by applying principles commonly used in ethics; specifically the principle of nonmaleficence and equal consideration of (like) interests. 
R. Humphreys

\section{Game Birds: the ethics of shooting for sport}

\section{Introduction}

Most birds shot by blood sport enthusiasts are raised in factory farms. Millions of birds are reared in small cages for up to three years for the purpose of shooting for sport. On such farms there is 'routine use of restraint and anti-aggression devices', such as 'bits' (plastic objects fixed in the birds' mouths), 'spectacles' (restricting the birds' vision), and 'bumpa-bits' (bits that cover the upper mandible). A recent inquiry indicates that these birds endure much suffering.*

As such, the practice of shooting game birds, such as partridges and pheasants, for sport poses significant ethical issues. This paper aims to provide an ethical assessment of shooting animals for sport, in particular, the use of birds for shooting, by applying principles commonly used in ethics; specifically the principles of equal consideration of (like) interests, and nonmaleficence.

Considering the fact that birds have interests ${ }^{+}$(including interests in life and not suffering), what are the ethical implications of factory farming birds for blood sports? Indeed, in light of the suffering that game birds endure in factory farms, it may be that shooting such birds for sport is more morally problematic than other types of hunting and shooting which many people are often fiercely opposed to, such as fox hunting or shooting 'higher' mammals, for while it seems plausible to say that some

\footnotetext{
${ }^{*}$ This information is sourced from Hickman in The Independent, $22^{\text {nd }}$ November 2008. Hickman cites the Farm Animal Welfare Council (FAWC), League Against Cruel Sports, and Animal Aid. His article reports on the first official inquiry into the rearing of game birds by the FAWC in November 2008.

+ Those beings that have interests are those beings who are capable of being harmed and benefited and have a good of their own (Feinberg 1974, p.51; Goodpaster 1978, pp.308-322.). While this view tends to be supported in the animal ethics literature, there is an ongoing debate about whether interests belong to sentient beings only or to all living things. For example, while Joel Feinberg believes that only sentient beings possess interests (Feinberg 1974, p.51), Kenneth Goodpaster argues that all living things (that is, sentient and nonsentient) have interests (Goodpaster 1978, pp.308-322). However, for the purposes of this paper it is sufficient to consider the interests of sentient beings only (specifically birds and humans). It is clear that birds do have interests, since they can be harmed and benefited and do have a good of their own.
} 


\section{R. Humphreys}

animals may be harmed more by death than others (due to, say, their greater capacities), there may be harms that are worse than death (such as a life of intolerable suffering).

The public image of game as a sustainable and cruelty-free source of meat (it is often believed that the birds shot are wild and live a life natural to their kind), and as an ethical option compared to some other meat products, is far from the truth. This paper will present a more realistic view of the ethics of rearing birds for shooting by blood sport enthusiasts. By making some comparative judgments based on considerations of interests in life and interests in not suffering, in relation to different animals used for different methods of killing in blood sports (and in light of an assessment of the use of game birds for blood sport), it will be argued that rearing pheasants and partridges in battery cages for shooting appears to be unjustifiable and, contrary to public opinion, our use of these birds may be more ethically problematic in comparison to some other blood sport activities.

The principles will be firstly outlined followed by a discussion of interests and harms, and a subsequent application of the principles to two basic interests: not suffering and life. One should then be in a better position to make some comparative judgments based on these interests in relation to blood sports.

I will use the term 'blood sports' to refer to those sports that involve killing animals. While the term 'country sports' is sometimes preferred to 'blood sports', I believe 'blood sports' is more accurate term to describe the killing of animals for sport. Indeed, the term 'blood sport' is referred to in the dictionary as 'any sport involving the killing of an animal' (Collins English Dictionary, 1996), but the term 'country sport' is not referred to. Admittedly, it could be questioned as to whether socalled 'blood sports', including hunting and shooting for 'sport', are actually 'sports' 


\section{R. Humphreys}

at all, in the ordinary sense, since the animals involved do not willingly partake in the pastime and nor could they be said to be involved in an activity for leisure, competition or exercise. In spite of this, hunting and shooting animals (for pleasure and leisure) are generally classed as 'sports' and so, for the purposes of this paper, I will call them 'blood sports'.

\section{The Principle of Equal Consideration.}

The principle of equal consideration is commonly used in our moral dealings with humans* and requires that the interests of one being be given equal consideration to the like interests of another being (Singer, 1995b, p.57.). Some philosophers, such as Peter Singer, have argued that the principle requires us to take the interests of not just humans seriously, but animals too:

The argument for extending the principle of equality beyond our own species is simple, so simple that it amounts to no more than a clear understanding of the nature of the principle of equal consideration of interests (Singer, 1995b, p.56.).

Sentient animals can suffer and, as such, they have (at the very least) an interest in not suffering. Since sentient animals do have interests and the principle is applicable to beings with interests, Singer argues that we should extend the principle to sentient animals, and that their interests be given equal consideration to the like interests of humans (Singer, 1995b, pp.57-8.).

It should be said that one need not support the view that animals should be given equal consideration in order to accept that animals have interests that should be considered. Indeed, for the purposes of this paper it is enough to suppose that animals do have interests and that, as David DeGrazia says, since 'ethics is centrally

\footnotetext{
${ }^{*}$ The equality of human beings rests on the principle of equal consideration of interests.
} 


\section{R. Humphreys}

concerned with interests', animals should be given, at least, serious consideration in ethics (DeGrazia, 1996, p.39.).

Being free from suffering seems to be an interest that sentient animals do have equally, or at least, do have. However, animals do not just have an interest in avoiding suffering. All animals have an interest in life or living, even if they do not seem to take an interest in life or living. Although, as Singer says, it does not follow that those lives have equal value (Singer, 1995b, p.107.).

It is not unreasonable to suppose that different lives have different value in respect of different capacities and potentialities. Indeed, Singer argues that 'the life of a self-aware being, capable of abstract thought, of planning for the future, of complex acts of communication, and so on, is more valuable than a being without these capacities' (1995a, p.20.). To kill creatures that possess such capacities is to deprive them of future goals, plans and potentials (Singer, 1995a, p.21.). Further one generally finds that beings who possess these capacities to a great extent have more complex lives than those whose capacities are somewhat limited in comparison. There appears to be a correlation between the possession of capacities and complexity of life.

The greater a being's capacities the more it stands to lose from death. Death deprives creatures from developing and fulfilling all those potentialities and capacities that they could have fulfilled in life. As Attfield argues, 'Death is a deprivation... for... nonhuman creatures whose essential capacities are unfulfilled. But the greater the extent to which creatures are capable of plans and projects... or of the development of conscious relationships, the more they stand to be deprived from death, and the more value is present in the kind of lives which they lead' (1995, p.90).

For example, an elephant may stand to lose more from death than, say, a bird, and a bird may lose more from death than, say, an ant. 
R. Humphreys

And what is of varying value may not only be life:

If the goods that my freedom permits are, on the whole, more prudentially valuable than what a bird's freedom permits, then equal consideration does not confer equal moral weight on my freedom and the bird's (DeGrazia, 1996, p.234.).

As DeGrazia says, 'For A's interest X and B's interest $\mathrm{Y}$ to be relevantly similar, A and $\mathrm{B}$ must have, in some sense, the same thing at stake with $\mathrm{X}$ and $\mathrm{Y}^{\prime}$ (DeGrazia, 1996, p.233.). Comparative claims can be made whilst taking into account the principle of equal consideration. Those comparative claims can be not just about life, but about other interests too, such as functioning properly, freedom, and being free from pain.

\section{The Principle of Nonmaleficence.}

Interests and harms are intimately connected, since interests belong to those things that can be beneficiaries, or can be harmed and benefited (Feinberg, 1974;

Goodpaster, 1978). It is reasonable to suppose that we can make ethical judgments about how animals are treated by considering the ways in which they can be harmed. While there seems to be some dispute about whether the interests of animals are morally important or relevant, there is less dispute about the ways in which animals can be harmed. If one considers how animals are harmed in light of specific interests it should enable one to see why those interests are morally relevant. It seems appropriate then to consider another principle in ethics that specifically takes harms into account: the principle of nonmaleficence. This principle could be seen to complement the principle of equal consideration in providing a framework in which the interests of animals, and the ways in which they can be harmed in light of those interests, can be thoroughly evaluated. 


\section{R. Humphreys}

The principle of nonmaleficence 'states a prima facie duty not to harm' (DeGrazia, 1996, p.259.). Obligations naturally arise from this principle, and arise from reflection on the ways in which beings can be harmed. As DeGrazia says, the most obvious way in which sentient animals are harmed is through suffering; and in his view, arising from the principle of nonmaleficence are 'obligations not to cause unnecessary suffering' (1996, p.262.). Since animals can be harmed this principle should apply to them.

What counts as necessary is, of course, debatable. But if we combine obligations not to cause suffering with the principle of equal consideration, a principle that requires that we 'Apply equally any standards that allow the causing of suffering', then, 'coupled with reasonable assumptions about the ethical treatment of humans, it has very far reaching implications for animals' (DeGrazia, 1996, p.264.).

\section{Interests and Harms}

Since birds can be harmed and do have interests, any adequate ethical assessment of the use of birds for blood sport will have to take interests and harms into consideration. So how are game birds harmed in light of their interests?

DeGrazia says that we have 'obligations, flowing from nonmaleficence, regarding... freedom (or liberty, the lack of constraints), functioning, and experiential well-being considered instrumentally' (1996, pp.268-69.). Freedom, functioning and well-being are basic interests that have an instrumental role and value in that they allow sentient animals to lead satisfying lives (DeGrazia, 1996, pp.268-72) and exercise species-specific tendencies.*

\footnotetext{
* Similarly, Robert Heeger and Franz Brom stress the value of an animal's feeling well, functioning well and leading a natural life (2001, pp.241-42.). I believe that saying that an animal should feel well, function well and lead a natural life is a simple yet clear and revealing formulation of an animal's basic interests. However, whether one says that an animal has an interest in freedom, functioning and wellbeing (as DeGrazia does), or that an animal should feel well, function well and lead a natural life (as Heeger and Brom do) is of little significance. Both involve the same major instrumental goods that
} 


\section{R. Humphreys}

In terms of animals' interests in freedom, what counts as harmful confinement for one may not be harmful for another. But, generally, confinement that restricts an animal from exercising its natural tendencies constitutes a harm. DeGrazia defines confinement as 'the imposition of external constraints on movement that significantly interfere with one's ability to live a good life' (1996, p.269.). Game birds raised in battery cages are significantly harmed from the confinement they endure, and restricted from exercising their species-specific capacities.

Disabling an animal so that it cannot function properly also constitutes a harm. DeGrazia defines disabling as 'damaging someone's ability to function in a way that significantly interferes with her ability to live a good life' (1996, p.271.). Disability of animals occurs frequently on factory farms, often due to confinement. Birds reared in battery cages for blood sport are significantly harmed through disability, and prevented from functioning properly by the use of bits.

Further, being free from aversive states is essential for one's experiential wellbeing (DeGrazia, 1996, p.255.). Causing an animal to feel prolonged aversive states, like pain, stress, and discomfort, prevents an animal from feeling well and interferes with its ability to live a good life and, in this way, constitutes a harm. Given that game birds in battery farms are harmed through confinement and disability, it is clear that they are certainly prevented from feeling well.

But freedom, functioning and well-being are not the only interests birds have. They also have an interest in living, or life, and are, therefore, harmed by premature death. As game birds are purposely bred for shooting, then their life interests are almost certainly harmed. However, taking into account the principle of equal 


\section{R. Humphreys}

consideration we can recognize that one being's interest in living, or life, may be different from another being's interest in living, or life. All lives are not of equal value, and death may be a greater harm for some animals than for others.

Indeed, as DeGrazia says, 'How one understands the strength of the presumption against killing normal members of a particular species will depend, to some extent, on one's interspecific value theory' (1996, p.265.). But, whatever one's value theory, there are obligations, that arise from the principle of nonmaleficence, against killing sentient beings. Since sentient animals are harmed by death we have a prima facie duty not to kill them. DeGrazia gives a definition of such an obligation in the form of a principle, which is 'Don't kill sentient animals unnecessarily'

(DeGrazia, 1996, p.265.).*

\section{Applying the Principles}

Harms then can be caused through a disregard for a being's interests, and can result in prolonged suffering. Birds raised in factory farms for blood sport suffer such harms. Indeed, the practice of raising birds in battery farms does not even consider birds' basic interests in not suffering and life. If we consider just these two basic interests (that is, not suffering and life) then, informed by the principles of nonmaleficence and equal consideration, these will suffice to show that rearing birds in battery cages for sport is unjustifiable, as is shooting birds for sport.

If one firstly takes into account interests in not suffering, informed by the principles, even shooting-sports that cause the minimum possible suffering appear

\footnotetext{
* Again, what is deemed to be a necessary sacrifice of animals' interests (specifically, here, their interest in living) is controversial. However, what is deemed a necessary human death is perhaps not so controversial, and perhaps we should consider that our preparedness to kill animals for any human purpose, and for whatever benefit (however trivial) might obtain, may be unreasonable and may indicate a bias in our thoughts about animals on the one hand, and humans on the other. In order to consider what counts as the necessary death of animals we should seriously consider all interests that are at stake, human as well as animal interests, rather than just suppose that any human interest should always take precedence over an animal's interest.
} 


\section{R. Humphreys}

unjustifiable. If the suffering of animals is given equal consideration to the like suffering of humans (or even just serious consideration), then the suffering of birds in battery farms, or other animals shot for sport, cannot be justified by appeals to an enthusiasm for shooting. Obviously we would consider it unjustifiable to inflict such suffering on humans, even if it was for weighty human interests, rather than an enthusiasm for game birding. This enthusiasm is not a weighty enough reason to override interests in not suffering.

The reply may be anticipated that, although birds suffer in battery conditions, the suffering some humans would have to endure if they could not shoot birds for sport overrides the birds' interests in not suffering. However, having to experience a life without shooting birds is not suffering. Choosing to pursue such a sport is usually about enjoying or preferring a particular activity, rather than satisfying basic needs or interests.

Admittedly, participating in a particular sport, such as hunting, could also be seen in terms of pursuing a project in life, and it could be argued that sporting activities are projects that contribute to the good life. This may be true, but basic needs need to be satisfied in order to pursue central projects. Indeed, for the majority of the world's population pursuing projects is a distant ideal, since their day-to-day lives are taken up by the struggle to survive in the form of attempting to satisfy basic needs. As such, interests in satisfying basic needs could be seen to be interests of a more weighty kind than interests or preferences in pursuing particular projects. Indeed, that basic interests are initially satisfied is of fundamental importance in pursuing goals in the form of sporting activities.

It is reasonable to suppose that, when considering conflicting human interests, basic needs or interests (such as freedom, functioning, well-being, not suffering or 


\section{R. Humphreys}

life) should take moral precedence over preferences, enjoyments or interests in pursuing certain activities. There is no reason to suppose that this should not be the case when we consider conflicting interests that involve nonhuman beings. That is, when the conflict involves the basic interests of nonhuman beings and, say, the preferences of humans, the basic interests of the nonhuman beings should take moral precedence (Attfield, 1995, p.91.).

Now if one secondly considers life interests then, informed by the principles, the killing of animals for enjoyment is wrong, even if those animals have lived a good life and their deaths are relatively painless. Despite the fact that some animals shot for sport may have had good lives and may be killed quickly, they have interests other than interests in not suffering. Most importantly, they have an interest in life; a basic interest that is overridden by an enthusiasm for game birding. But, again, such enthusiasm is not a weighty enough reason to override a being's life interest.

Such an interest, however, may be justifiably overridden, and it does not follow that if shooting animals for sport is wrong then all shooting of animals is always wrong. Not all beings have like life interests, and the principle of equal consideration allows for comparative judgments to be made. So shooting may be justifiable in some circumstances, other than for sport. But such a basic interest should not be overridden by appeals to an enthusiasm for certain pastimes.

When reared in battery farms for the purpose of shooting, birds' basic interests are overridden by the enjoyment or preference some humans have in pursing a certain sport, but, taking into account harms and the principle of equal consideration, it is hard to see how this can be justified. 


\section{R. Humphreys}

\section{The Argument From Existence}

However, there is an argument in favour of hunting that should be considered here, which is the argument from existence. Now, there are two forms that this argument can take. The first argues that the suffering caused to the animals (in this case, specifically birds) in factory farms is the price they have to pay for existing, for without being subjected to the factory farming system they would not have existed at all. However, the person who uses this argument could also use the same argument to justify the most vicious forms of slavery and other types of human exploitation. The same argument would also justify the cruel treatment of children by their parents on the grounds that were it not for their parents then they would have not have been born at all. The immense distress of game birds cannot be compensated for by their existence. If a being's life or existence is not worthwhile then it cannot compensate for his / her pains and distresses (Clark, 1984, p.59.). This argument then should be rejected as implausible.

The second way the argument is presented is as follows. While the suffering of birds raised in factory farming conditions is wrong and cannot be compensated for by their existence, the killing and shooting of birds (for sport) not raised in such conditions (but raised in good conditions) is not wrong, since were they not bred for sport they would not have existed, and it is better to have lived, and to have lived a relatively good life, than not to have lived at all (even if that life is destined to be cut short). Further, it is argued that if people were to stop shooting and hunting birds for sport then there would be no reason to breed these birds, and thus they would not have had a life at all. 


\section{R. Humphreys}

Now, this argument appears to be more cogent than the former one. If game birds are reared in conditions that promote their welfare then it is likely that they will live lives in which their needs and interests are taken into account (apart from their interest in life of course). Further the living of a relatively good life may outweigh the harm caused by a premature death. This seems plausible, but if we assume that the birds do have worthwhile lives, the living of which outweighs the harm caused by a premature death, a problem still arises from the fact that the birds are killed yet do have an existence that is worthwhile, for, as Stephen Clark says, if a being's life or existence is worthwhile, then to kill that being and end its existence is to injure it (Clark, 1984, p.59.). In other words, while it is true that the birds would not have existed were they not bred for hunting and killing, and that if one removes the hunt one would also remove the future existence of many game birds, this in itself does not justify their killing.

Further, the motives for bringing beings into existence in order that they will be killed are important to the ethics of generating such lives and the killing of such beings. For example, there may be cases in which there are significant interests at stake; interests that depend on the bringing of beings into existence and the killing of those beings. The life interests of the beings brought into existence, in such cases, may be less weighty than the interests for which their lives are 'sacrificed' (or may be less significant than other interests at stake). But bringing birds into existence for the sole purpose of sport does not seem to be a weighty enough motive / purpose to justify the act of generating beings (in this case, birds) for killing. As far as future game birds are concerned, we may have a negative obligation not to bring them into existence when we know they will suffer a premature death for the purpose of sport. Bringing lives into existence is a serious moral act, and those that decide to act to 


\section{R. Humphreys}

bring beings into existence have a strong responsibility for seriously considering the interests of those beings (Attfield, 1998, p.188.), including their interests in life.

Also, we do not see people that do not have children or decide not to have children (but could have children that would lead a good life), as having positive obligations to bring into existence children in order that they might live good lives*, and the same reasoning could apply to the second form of the argument from existence. That is, there is no reason to suppose that we have obligations to bring game birds into existence when we know they will not live in the conditions of the factory farm, and there is no reason to think that breeding birds for sport serves some kind of moral purpose for bringing beings into existence that would not have lived were they not bred for killing in sporting activities.

Further, the second form of the argument from existence implies that if a practice existed whereby humans were bred specifically to be shot for sport (say as slaves to be used in sporting activities) then that practice would be morally right, and that it would be right to support the continuance of such a practice if the humans lived in humane conditions and their interests were taken into account. In line with the second form of the argument, it could be analogously argued that if such humans had not been bred to be killed and suffer a premature death then they would not have existed at all, and (for these humans) it is better that they should live and live a life which is relatively good, than not to have lived at all, even if their lives are ones which will be cut short.

However, while it may be true that it is better to live a relatively good life, even one that will be purposely cut short, than not to have lived at all, this is no

\footnotetext{
* Saul Smilansky, however, argues that, in certain circumstances, some people could have responsibilities to have children (1995, pp.42-53.).
} 


\section{R. Humphreys}

justification for a practice which aims to breed beings in order to kill them for sport. The very existence of the human sports-slaves in this hypothetical example (above) seems to be no justification for their killing or for a practice which breeds them for sport. Of course we could argue that for these humans it is better that they have lived and lived a relatively good life than not to have lived at all, but the fact that they do exist does not provide a justification for the practice that brought them into existence.

For further clarity, let us apply the second form of the argument from existence to an example that is not hypothetical. Rape is immoral, yet sometimes the act results in a human life being brought into existence. For the human that exists as the result of rape, it is better than he / she had lived than not to have lived at all, and of course if there were no rapists then there would be no lives generated from the act of rape. Now, the argument from existence (as it was applied to hunting) implies that the lives of these humans somehow justify the act of rape itself - were it not for the act of rape then they would not have existed and it is better to have lived than not to have lived at all. (The argument from existence, applied to hunting, argues that were it not for hunting then game birds would not have existed at all.) However, that humans exist as a result of rape is no justification for rape. It may be better for these humans that they have lived and lived a good life than not to have lived at all, but this does not justify the rapist's act. Analogously, that a practice generates birds for the purpose of sport (birds that would not have lived were it not for the existence of blood sports) does not appear to a justification for such a practice.

At first sight then the second form of the argument from existence seems reasonable (and is certainly more cogent than the first form of the argument, since it does not view the existence of game birds as compensation for their misery), yet on closer inspection it is problematic and, just like the first argument from existence, 


\section{R. Humphreys}

could be used as an attempted justification for certain forms of slavery, such as human sports-slaves. As such, it should be rejected. While the argument from existence does not provide a justification for rearing birds to be killed for sport, or for killing birds for sport, rearing animals to be killed for other purposes has not been ruled out (as long as the interests at stake are weighty enough to override the life interests of the animals concerned and the animals are reared in conditions that promote their welfare).

\section{Comparative Judgments.}

In spite of the arguments above, people who take part in blood sport continue to show a strong commitment to this pastime. Therefore, it is wise to point out that some methods of killing for sport appear to be better moral choices than others, if only because they cause less suffering. Certainly, different beings do have different interests. So we may be able to make some comparative judgments based on interests in life and not suffering.

Considering, briefly, just life interests, killing a pheasant appears less problematic than killing a tiger, perhaps because tigers have more complex lives and, arguably, greater capacities than pheasants. While birds of certain species, like parrots, have been found to have highly developed cognitive abilities, including the ability to form categorical classes, complex communication skills, and even language skills (Pepperberg, 1999), it is not obvious that such capacities extend to pheasants. The behaviour of pheasants (and of other large commercially bred birds) suggests that they have limited capacities compared to other species of birds. Most prominently, they do not express the complex communicative behaviours (such as complicated bird song) of other birds. This is not to say that they are not capable of certain abilities, 


\section{R. Humphreys}

such as problem solving and some communication skills, but only to say that their abilities are not as developed as the abilities of some other species.

The behaviour of tigers is certainly indicative of more highly developed cognitive capacities than pheasants, including greater awareness and understanding of their surroundings, long-term memory, the flexibility to adapt to changes in their environment (wild animals must be able to adapt to changing environments and surroundings in order to survive), and the ability to be selective of the information that they process (for example, the ability to ignore some prey animals, while choosing to pursue others instead). In respect of their capacities and potentialities, it appears that tigers stand to loose more from death than pheasants and, as such, could be seen to have a greater interest in life.

Now let us consider a being's interests in freedom, functioning and well-being, and thus a being's interest in not suffering, and let us suppose that the suffering of game birds may be of such an intensity that it is a harm worse than death itself, that is, the extent of the disregard for their interests in not suffering constitutes a greater harm than the disregard for their interests in life. And let us further suppose that, taking into account the principle of equal consideration, if such suffering were inflicted upon other beings shot for sport, then this suffering also would be worse than death itself for those beings.

So, we are assuming that game birds in factory farms endure such suffering that it constitutes a harm worse than death, and that if other beings were to experience like suffering then, for them also, it would constitute a harm worse than death.

If we now compare the interests of these birds to the interests of other beings shot for sport, it may serve to highlight just how indefensible our treatment of game birds (in factory farms) actually is. We can easily think of certain animals whose 


\section{R. Humphreys}

shooting for sport is (usually) considered by many people as unjustifiable, or, at least, unacceptable. But we may find that shooting such animals would be less morally problematic than our current treatment of birds for blood sport, where that treatment involves rearing birds in battery cages, yet the treatment of game birds is rarely questioned.

Now, returning to the above scenario (where the suffering birds endure in factory farms constitutes a harm worse than death for all beings that experience it), and taking into account the principle of equal consideration, it seems that rearing birds in battery cages, for the purpose of shooting for sport, appears to be more problematic than shooting a wild tiger that has lived a good life (assuming the killing does not cause such suffering). The reason for this is that suffering appears to be something that all sentient beings, whatever their species, can experience (whether they can experience certain types of suffering equally or not)*, and we are assuming that the suffering is of such an extent that it constitutes a greater harm than death for all beings who endure it, whatever the life interests of those beings may be.

\footnotetext{
* It seems reasonable to suppose that the different mental abilities of animals (and humans) may cause different degrees of suffering in different creatures. Singer makes this point: 'There are many matters in which the superior mental powers of normal adult humans make a difference: anticipation, more detailed memory, greater knowledge of what is happening, and so on' (1995a, p.16.). It may be that humans possess certain mental capacities (such as anticipation and reasoning skills) to a greater degree than animals, and that this causes humans to suffer more than animals in similar circumstances. However, it is not clear that having 'higher' mental capacities always causes a being to suffer more than a being with so-called 'lower' mental capacities. It may be that animals that lack certain capacities, or possess certain capacities to a lesser degree than humans, suffer more than humans in comparable circumstances. Animals may lack a full understanding of certain situations, and this may prevent them from being able to rationalise what is happening around them or to them. As Singer claims, 'Sometimes animals may suffer more because of their more limited understanding. If, for instance, we are taking prisoners in wartime we can explain to them that although they must submit to capture... they will not otherwise be harmed... If we capture wild animals, however, we cannot explain that we are not threatening their lives. A wild animal cannot distinguish between an attempt to overpower and confine from an attempt to kill; the one causes as much terror as the other' (Singer, 1995a, p.16). That said it is just not clear the extent to which different individual creatures, and beings belonging to different species, can suffer. Even individual humans experience suffering in varying degrees in comparable situations. What is clear though is that animals can suffer. In respect of this paper, we do not need to know the exact degree to which birds can suffer in order to recognise their sufferings.
} 


\section{R. Humphreys}

While it seems fair to say that the life interests of tigers should (all other things being equal) override the life interests of birds, this does not in any way support the claim that tigers' life interests should always override birds' interests in not suffering, especially where that suffering would be so intense as to constitute a harm worse than death (as in the above scenario).

On the factory farm few of the birds' basic interests are taken into account. They are made to endure prolonged suffering, through confinement, disability and a lack of consideration for their well-being. In the above case of the tigers, however, they have had a good life and are spared from the type of suffering that may constitute a worse harm than death. Of course they are harmed by death, but they have not been made to endure a harm worse than death (assuming they have lived in the wild).

So, the fact that some blood sports cause great suffering makes those sports more ethically problematic than others, whatever the life interests of the beings involved. Life interests may not always override interests in not suffering, particularly when that suffering is of such an extent that it is a harm worse than death. As such it may be more indefensible to subject birds to such suffering than to shoot, what are thought to be, more complex animals with greater interests in life and which have not been made to endure intolerable suffering.

However, some types of blood sport do cause relevantly less suffering than others. So, again, if we take interests in not suffering into account, but now consider beings with like interests in life, the use of battery birds for shooting is clearly more problematic than the use of free-range birds for shooting. Battery birds are caused more suffering than free range ones.

But different animals have different life interests, and if we consider life interests of wild animals and game birds shot for sport, shooting some wild animals 


\section{R. Humphreys}

(like tigers) appears to be more problematic than the shooting of game birds reared in free-range systems. Neither free-range reared game birds nor wild animals are made to endure a life of suffering for sport, and both will suffer when they are shot. But harm caused by death is not the same for all animals, and death appears to be a greater harm for some wild animals than for game birds. However, as said above, shooting wild animals may be less problematic than the use of birds reared in battery farms for sport, where the suffering such birds endure is great.

Also, hunting (for sport) with rifles appears clearly less problematic than hunting with traps (like snares or leg hold traps), if we assume that the former causes less suffering than the latter and the shooting does not involve animals bred in battery conditions. Hunting with traps often involves animals being trapped for days on end with horrific injuries. The animals often starve to death or die of exposure. Further, animals killed by traps are usually wild animals and may often be animals in which the harm caused by death is greater than the harm caused by death for animals bred specifically for blood sports. (Monkeys and large cats are just some of the animals hunted with snares. Wild cats, such as leopards and bobcats, are also victims of leghold traps.) Therefore, it is difficult to see how hunting with snares or traps is ever justifiable and appears to be a worse choice than shooting birds reared in free-range conditions or shooting animals in general.

So, taking into account the principles of equal consideration and nonmaleficence, and considering interests in life and not suffering, it appears that, although blood sports are unjustifiable, some types cause more harm to animals and give less consideration to their interests than others. While there are reasons for supposing that some types of killing for sport are better moral choices than others, the 


\section{R. Humphreys}

practice of rearing birds in battery cages for sport, or hunting with traps, can never be justified, and appear to the most ethically problematic.

Such considerations may be hard to undertake by game bird enthusiasts. They may argue that the lives of game birds are less significant compared to the lives of large wild mammals. This may be true. Indeed, considering the life interests of different beings, although all sentient beings have an interest in not suffering, not all beings have an equal interest in life and, therefore, some beings may be harmed more by death than others. However, there are harms other than death. Animals have interests other than interests in life, and it may be that there are forms of suffering that are of a greater harm than the harm caused by death, and that wild animals that are shot for sport are caused less harm than factory-farmed birds used for shooting, and, furthermore, that the interests of such birds are given little consideration in comparison to the interests of wild animals shot for sport. Such conclusions are of utmost importance for the ethics of shooting birds for sport and, if taken seriously, may have weighty implications for blood sport as a practice.

\section{Bibliography}

Attfield, Robin. 1998. 'Intrinsic Value and Transgenic Animals', Animal

Biotechnology and Ethics, eds. Holland and Johnson. London: Chapman and Hall.

Attfield, Robin. 1995. Value, Obligation, and Meta-Ethics. Value Inquiry Book Series, 30. Amsterdam - Atlanta, GA: Rodopi.

Clark, Stephen. 1984. The Moral Status of Animals. Oxford: Oxford University Press. Collins English Dictionary. 1996. HarperCollins.

DeGrazia, David. 1996. Taking Animals Seriously. Cambridge: Cambridge University Press.

Farm Animal Welfare Council. Nov. 2008. Opinion on the Welfare of Game Birds. London: FAWC. 
R. Humphreys

Feinberg, Joel. 1974. 'The Rights of Animals and Unborn Generations', Philosophy and Environmental Crisis, ed. William T. Blackstone. Athens: University of Georgia Press.

Goodpaster, Kenneth. 1978. 'On Being Morally Considerable', Journal of Philosophy. 75.

Heeger, Robert, and Brom, Frans W.A. 2001. 'Intrinsic Value and Direct Duties: From Animal Ethics Towards Environmental Ethics?', Journal of Agricultural and Environmental Ethics. 14 (2 ): 241-42.

Hickman, Martin. 22 ${ }^{\text {nd }}$ November 2008. 'Exposed: the cruel rearing of game birds', The Independent. Hickman cites the Farm Animal Welfare Council, League Against Cruel Sports, and Animal Aid. His article reports on the first official inquiry into the rearing of game birds by the FAWC (reference above for this report).

Singer, Peter. 1995a. Animal Liberation, second edition. London: Pimlico Press.

Singer, Peter. 1995b. Practical Ethics, second edition. Cambridge: Cambridge University Press.

Smilansky, Saul. 1995. 'Is There a Moral Obligation to have Children?', Journal of Applied Philosophy. 12 (1): 42-53. 